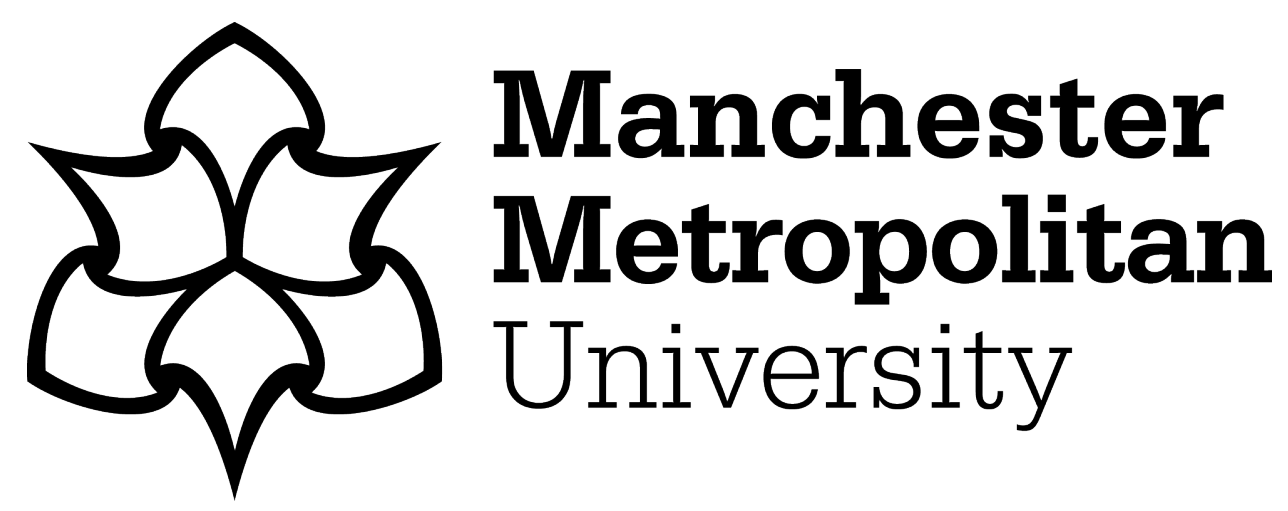

Rampasso, IS, Siqueira, RG, Martins, VWB, Anholon, R, Quelhas, OLG, Leal Filho, W, Lange Salvia, A and Santa-Eulalia, LA (2021) Implementing social projects with undergraduate students: an analysis of essential characteristics. International Journal of Sustainability in Higher Education, 22 (1). pp. 198-214. ISSN 1467-6370

Downloaded from: https://e-space.mmu.ac.uk/626877/

Version: Accepted Version

Publisher: Emerald

DOI: https://doi.org/10.1108/IJSHE-11-2019-0323

Please cite the published version 


\section{Business models towards the SDGs: the barriers for operationalizing Product-Service System (PSS) in Brazil}

Labbate, Renato ${ }^{\text {a. Silva, Rodrigo Farias }}$; Rampasso, Izabela Simon ${ }^{\mathrm{a}, \mathrm{b} *}$;

Anholon, Rosley; ; Quelhas, Osvaldo L. G ${ }^{\text {c }}$ Leal Filho, Walter ${ }^{\mathrm{d}}$

International Journal of Sustainable Development and World Ecology 01 Jan 2020

DOI https://www.tandfonline.com/doi/full/10.1080/13504509.2020.1823517

${ }^{a}$ School of Mechanical Engineering, University of Campinas, Brazil. Mendeleyev Street, 200. Campinas, São Paulo, Brazil; ' ${ }^{b}$ PND/CAPES Program, Doctoral Program in Sustainable Management Systems. Federal Fluminense University, Brazil. Passo da Pátria Street, 156. Niterói, Rio de Janeiro, Brazil; ' Master Program in Management Systems and Doctoral Program in Sustainable Management Systems. Federal Fluminense University, Brazil. Passo da Pátria Street, 156. Niterói, Rio de Janeiro, Brazil; ${ }^{d}$ Hamburg University of Applied Sciences. Faculty of Life Sciences Lohbruegger Kirchstraße 65, Sector S4, Hamburg Germany.

*corresponding author: izarampasso@gmail.com

\section{Acknowledgements}

This work was supported by the Conselho Nacional de Desenvolvimento Científico e Tecnológico (CNPq) under Grants 307536/2018-1 and 305442/2018-0; and by Coordenação de Aperfeiçoamento de Pessoal de Nível Superior - Brasil (CAPES) Finance Code 001, under process 88887.464433/2019-00.

\section{Data availability statement}

The data that support the findings of this study are available from the corresponding author, ISR, upon reasonable request. 


\title{
Business models towards SDGs: the barriers for operationalizing Product-Service System (PSS) in Brazil
}

\author{
Sustainable development requires the creation and development of new business \\ models. Sharing economy will maximize the use of a product by several people, \\ while it enables the reduction of natural resources consumption. In this sense, \\ Product-Service Systems (PSS) can greatly contribute to achieving the \\ Sustainable Development Goals, published by the United Nations. In this context, \\ the present study aims to analyse the barriers associated with the \\ operationalization of PSS business models in Brazil. Nineteen barriers listed in \\ the literature supported a questionnaire used in a survey of Brazilian researchers. \\ Data analysis was performed through Hierarchical Cluster Analysis, descriptive \\ statistics and TOPSIS (Technique for Order of Preference by Similarity to Ideal \\ Solution). TOPSIS is used for comparative ordering of barriers in terms of \\ intensity. The results showed that there are many barriers observed in the \\ Brazilian scenario for the operationalization of PSS; those related to the \\ resistance to change to the mentioned business models and the lack of necessary \\ skills to manage them stood out. These findings can be used to enhance the \\ debates about PSS in the Brazilian context.
}

Keywords: Product-Service System; Sustainability; SDG 9; SDG 12; barriers; Brazil.

\section{Introduction}

Sustainable development is a major concern in the world. The attention to economic, environmental and social aspects is decisive in the search for a better future (Park and Yoon 2015; Chiu and Tsai 2020). The negative impacts caused by human activities on the environment causes several negative results for people and the planet (OrdonezPonce and Khare 2020), such as water scarcity and climate change (Omer et al. 2020). Considering the magnitude of these consequences, society increasingly demands effective actions; inducing governments, institutions and companies to strive for 
sustainability goals (Franciosi et al. 2020; Zhang et al. 2020) throughout their whole supply chains (Amiri et al. 2020; Shete et al. 2020).

The Sustainable Development Goals (SDGs) published by the United Nations can be a useful tool for guiding companies towards a better future (UN 2015). For industry to be aligned with sharing economy concepts, SDGs 9 and 12 are profoundly important (Martins et al. 2020). SGD 9, named "Industries, Innovation and Infrastructure", establishes targets related to the creation of a sustainable infrastructure and industrialization, designed to consider social, economic, environmental and regional issues. In this goal, the greater need that developing countries present in relation to many of these targets is emphasised. Additionally, the relevance of scientific research and technological innovation for industrial sectors advancements is presented. Specifically, regarding the environment, target 9.4 highlights the need for industries to enhance the efficiency of resource utilization. Regarding SDG 12, titled "Sustainable consumption and production", the reduction of waste creation and the need to properly manage products lifecycle and production is mentioned. In this sense, "prevention, reduction, recycling and reuse" (p. 13) is pointed out as a means for waste reduction (UN 2019). According to Bali Swain and Yang-Wallentin (2020), developing countries should focus on SDGs 1-9 and 11-13. In this sense, it is possible to verify that SDGs 9 and 12 are important for developing countries, according to these authors.

Focusing on business managing context, organizations increasingly need to align their operation and innovation processes to the needs of all stakeholders. Therefore generating from diversified requirements new products, services or combined systems (Chofreh et al. 2018; Cegarra-Navarro et al. 2019; Bradley et al. 2020). The concept of Product-Service System (PSS) thus emerges. According to Mont (2019), PSS can be understood as the offer of the physical item associated with services, complemented by 
support networks and infrastructure; these systems are elaborated to be competitive, meet customer needs and cause lower environmental negative impacts than other business models.

For Tukker (2015), PSS can be considered as an effective instrument in guiding society towards the Circular Economy. This statement is corroborated by other authors (Reigado et al. 2017; D’Agostin et al. 2020). Sousa and Miguel (2015) and Catulli et al. (2017) argue that PSS represents a promising business model in the search for sustainable development, with advantages for all stakeholders. Yang and Evans (2019) points out that for many companies PSS offers differentiation possibilities and provides higher profit margins compared to product sales. Additionally, PSS enables greater revenues and increases the company's competitiveness.

Despite the positive perspectives presented above, it is important to mention that there are many barriers to the full adoption of PSS. An interesting study on the subject refers to the literature review conducted by Beuren et al. (2013) and sought to assess barriers to the adoption of PSS. Annarelli et al. (2016) also presented a systematic literature review about PSS and presented useful findings regarding drivers, benefits and barriers related to its adoption. Considering small and medium enterprises, Jesus Pacheco et al. (2019) performed a systematic literature review on the barriers related to PSS; in addition, the authors collected the lessons learned and guidelines presented in the literature on the subject. Focusing on the customer side, D'Agostin et al. (2020) performed a study on PSS barriers according to the perception of Brazilian young consumers living in small and medium cities. It should be noted that the barriers related to the scope of this research are detailed in the theoretical background.

The impact of cultural aspects on features and chances of success is emphasized in the literature, considering different countries or different segments in a country 
(Annarelli et al. 2016; Sousa-Zomer and Miguel 2016; Annarelli et al. 2020). SousaZomer and Miguel (2016) highlight the need for cultural analysis in PSS design and implementation, especially when considering the role of consumer habits in future consumption decisions. Within organizations, Annarelli et al. (2016) highlights the resistance to change within a organizational culture. Analysing the Brazilian context, there are unique characteristics that can impact the adoption of PSS models related to cultural features, such as management typology developed in companies and consumer habits.

Based on the information presented, this study aims to analyse the main barriers existing in Brazil for operationalizing PSS business models. This analysis will be made from information collected from specialists in the subject.

In addition to this introduction, this article consists of four more sections. Section two presents the theoretical foundation that underlies the study. Section three describes the methodological procedures developed. Section four presents the results achieved and associated debates, followed by section five, which presents the conclusions and final considerations.

\section{Theoretical background}

\subsection{PSS and the barriers associated to its implementation}

A PSS can be understood as a market proposal that incorporates additional services to the traditional functionality of a product. The emphasis is on "selling the use" instead of "selling the product". The customer pays for the use of an asset and not for its purchase (Akbar and Hoffmann 2019). Baines et al. (2007) mentions that the referred concept is a special case of servitization, and this information is corroborated by Corrêa (2018). 
In terms of business, PSSs are characterized by excellent opportunities for companies as the offer of certain products to the market begins to saturate; if well structured, a PSS allows new revenue streams and greater competitive advantage (Weking et al. 2018; Mont 2019; Yang and Evans 2019). However, it is important to mention that the achievement of these benefits will require deep knowledge about the product life cycle (Beuren et al. 2017), an acceptance level of consumers in a given region or segment in relation to the proposal (Mont et al. 2006; Annarelli et al. 2020), establishment of an infrastructure that supports PSS (Annarelli et al. 2016), and detailed studies of operating costs (Tukker 2015), among others. Vezzoli et al. (2015) corroborates the aforementioned point of view in terms of competitive differential and also mentions the possibility of companies disconnecting economic growth from environmental degradation.

Interesting examples of PSS are presented by Akbar and Hoffmann (2019) in their study. The authors focus on PSSs aimed at B2C, concentrating on examples such as car sharing (e.g. Zipcar), bicycle sharing (e.g. Citi Bike) and luxury fashion sharing (e.g. Bag Borrow). In these cases, customers use the products during a period of time, but these products are owned by suppliers that are in charge of quality and control of the products. Other examples can be seen in Cusumano et al. (2015), which mentions information technology companies such as Dell, IBM and SAP. According to these authors, these and other companies from the information technology sector are increasingly offering services while their revenue with products sales decrease.

It is important to mention that the more integrated a product manufacturer is (the owner and user of a product) the greater the added value to the PSS. For Pezzotta et al. (2016), methods and tools are needed to support all phases of design and development of a PSS, and in this sense, integration is essential. To satisfy the customers needs in 
terms of use, it is mandatory that the links involved promote knowledge exchange among them.

Boucher et al. (2016) argues that PSS can be characterized as a promising initiative for the establishment of sustainable production and consumption patterns. In the same line of reasoning, Zeeuw van der Laan and Aurisicchio (2020) mentions that PSSs can become great allies of Circular Economy models which seek alternatives to the production and consumption systems to deal with resource degradation and waste generation. In their study, these authors identified items related to PSS that contribute to closed loops and subdivided them into six architectural levels, namely: "services, resources, stakeholders, contract, value delivery and systems and tools" (p. 1). The results achieved by these authors points out the contributions of PSSs to achieving circularity.

PSS are directly linked to innovative and sustainable business models, increasingly attracting the interest of companies (Boons and Lüdeke-Freund 2013). However, it is important to mention that its adoption and benefits generation require planning and present several barriers. Table 1 presents these barriers according to the systematic reviews performed by Annarelli et al. (2016) and de Jesus Pacheco et al. (2019); it is also emphasized that this table presents the codes through which barriers will be identified in the results analysis.

Table 1. Barriers for operationalizing PSS models according to the academic literature (Source: Annarelli et al. (2016) and de Jesus Pacheco et al. (2019))

\begin{tabular}{ll}
\hline Code & \multicolumn{1}{c}{ Barrier } \\
\hline B_1 & Lack of understanding or misunderstanding of the concept. \\
B_2 & Lack of financial resources. \\
B_3 & Low performance perspective. \\
B_4 & Difficulty in recognizing market demands. \\
B_5 & Low engagement in innovation activities. \\
B_6 & Lack of technological information and knowledge for implementation. \\
B_7 & Lack of qualified personnel. \\
B_8 & Lack of skills needed for business management. \\
B_9 & Negative prospects due to uncertainties. \\
\hline
\end{tabular}




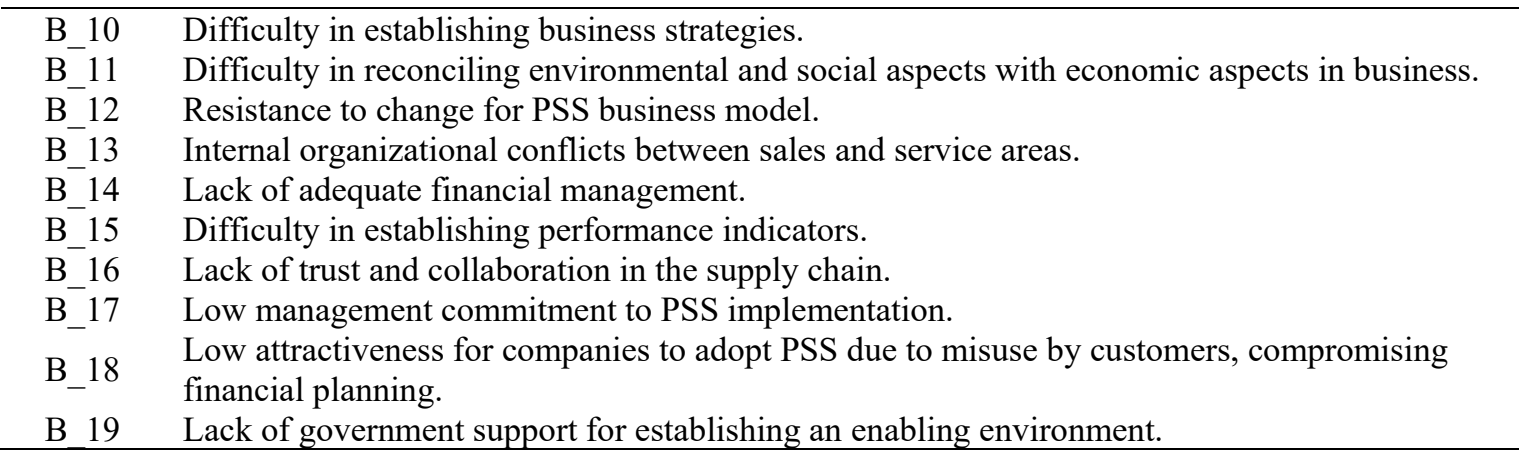

As mentioned in the introduction of this article, the existing barriers in adopting PSS business models are associated with cultural characteristics, management models developed by companies, and consumption habits by customers (which vary from country to country), as is corroborated by Sousa-Zomer and Miguel (2016). Thus, studies focusing on specific countries' realities can identify barriers according to each context.

Focusing on Brazil, there are few studies about PSS in the country. Most of them are composed of case analysis. Sousa and Miguel (2015) analysed a PSS business model of a "reverse osmosis water filter system" (p. 138) in Brazil, they debated the sustainability related implications of adopting a PSS and the need to consider sustainability aspects in order to ensure that it will be a sustainable PSS. Analysing two Brazilian cases of PSS, Sousa-Zomer and Miguel (2016) highlighted the need of governmental actions for creating policies and opportunities related to PSS, especially in developing countries since knowledge about PSS may be less disseminated in these regions. Homrich et al. (2017) investigated the sustainability of PSS used in small rural communities, analysing an olive oil processing case in Brazil. According to their findings, economic, social and environmental aspects of sustainability are met in the analysed PSS. Teles et al. (2018) analysed how PSS business models can enhance sustainability aspects through case studies related to electric car-sharing in Brazil. Regarding the environment, the main benefit is associated with gas emission reduction; 
social aspects, jobs creation and greater access for people to services and products can also be mentioned; for economic aspects, the lower operating costs may be cited. Pereira et al. (2019) analysed the healthcare industries of Brazil and Denmark, and verified the influence of the business ecosystem - whether provider-pushed or customer-pulled - on PSS features. Oliveira et al. (2018) studied the characteristics of the PSS business model of a Brazilian organization. Using a Canvas framework, the authors identified the main elements for a PSS business model.

In addition to these case analyses, three other studies about PSS in Brazil were found. Carvalho et al. (2020) proposed a PSS for Brazilian cities organic waste treatment in order to generate energy and reduce the use of dumps. Lermen et al. (2020) verified the interest of farmers in a sustainable PSS for grain drying and storage, performing a market analysis among options of PSS. In a survey with 104 companies from Brazil and Italy, Ayala et al. (2019) analysed the role of support of service suppliers in a PSS.

\section{Methodological procedures}

The development of this study was conducted through the following steps: 1) Bibliographic search on PSS and challenges associated to its operationalization; 2) Development of a questionnaire to be used in the survey; 3) Survey conduction with specialists in PSS which know about the Brazilian reality; 4) Data analysis, results presentation and debate of them considering the literature. Their details are better explained in the following paragraphs.

Initially, for establishing the theoretical background for this study, a literature search was conducted on PSS and associated barriers for its operationalization. Combinations of "PSS" and "Product-Service System" were used to develop the introduction and theoretical background sections. In this bibliographic search, two 
robust and recent systematic literature reviews were found: Annarelli et al. (2016) and Jesus Pacheco et al. (2019). Two observations need to be made: 1) for a greater operationalization of the questionnaire, some barriers were combined or summarized without losing content; 2) in Jesus Pacheco et al. (2019), they focused on small and medium enterprises; however, the barriers presented in their study can also be faced by large companies; in this sense, the focus of our questionnaire was made broader by considering organizations of any size. From the analysis of these two articles, nineteen barriers were defined which formed the basis of the questionnaire, as presented in Table 1.

These barriers were used to develop the questionnaire used in the survey. This questionnaire was composed of two parts, one dedicated to characterizing respondents' experience for their categorization and another part dedicated to barriers evaluation. Regarding the first part, respondents needed to answer questions on their academic training, their time of experience, their research area, and their involvement in research groups related to PSS. In the second part, respondents evaluated the barriers associated with PSS operationalization, according to their knowledge and considering the Brazilian reality. The scale for this ranged from 0 to 10 , in which 0 was for those barriers not observed in Brazilian reality and 10 was for the barriers observed in an intense level. It is important to mention that, before the survey, this questionnaire was approved by the Ethical Committee of Unicamp (CAAE: 29828920.4.0000.5404) for data collection. All respondents agreed to participate in this research through Google Forms.

In the third stage, the survey with specialists was performed. 208 invitations were sent, and after two months 50 answered questionnaires were received, which resulted in a response rate of $24.04 \%$. Data were collected through Google Forms. From the total of respondents, $8 \%$ had up to 5 years of experience, $38 \%$ had between 5 and 15 
years, and 54\% more than 15 years of experience. Regarding the greatest academic degree, $28 \%$ were specialists or masters and $72 \%$ had $\mathrm{PhD}$. All the respondents were researchers and their areas of research were: management (22\%), product development or sustainability (34\%), and PSS (44\%). In relation to their research group, $42 \%$ of the respondents did not participate in a research group related to PSS, 40\% participated in a group with this focus, and $18 \%$ of them coordinated a research group focused on PSS.

The last stage of this research was composed of data analysis. Initially, Hierarchical Cluster Analysis was used for grouping the specialists according to their similarities, considering the information they provided in the survey. According to Malhotra (2012), this technique aims to classify items into groups. In this research, the respondents were grouped according to their similarities. The codification used for this grouping is presented in Table 2 .

Table 2. Coding used to group the respondents.

\begin{tabular}{|c|c|c|c|}
\hline $\begin{array}{c}\text { Time of } \\
\text { experience } \\
\text { (V1) }\end{array}$ & $\begin{array}{c}\text { Greatest academic } \\
\text { training completed } \\
\text { (V2) }\end{array}$ & Research area (V3) & $\begin{array}{c}\text { Involvement in research groups } \\
\text { related to PSS (V4) }\end{array}$ \\
\hline $\begin{array}{c}1=\text { up to } 5 \\
\text { years. }\end{array}$ & $1=$ Graduation & $\begin{array}{c}1=\text { Research in } \\
\text { management area. }\end{array}$ & $\begin{array}{l}1=\text { The respondent does not } \\
\text { participate in a research group } \\
\text { related to PSS theme. }\end{array}$ \\
\hline $\begin{array}{c}2=\text { between } 5 \\
\text { and 15 years. }\end{array}$ & $\begin{array}{c}2=\text { Specialization } \\
\text { and/or masters. }\end{array}$ & $\begin{array}{c}2=\text { Research in product } \\
\text { development or } \\
\text { sustainability areas. }\end{array}$ & $\begin{array}{c}2=\text { The respondent participates } \\
\text { in research group(s) related to } \\
\text { PSS theme. }\end{array}$ \\
\hline $\begin{array}{c}3=\text { more than } \\
15 \text { years. }\end{array}$ & $3=$ Doctorate. & $\begin{array}{c}\text { Research related to } \\
\text { PSS. }\end{array}$ & $\begin{array}{c}3=\text { The respondent coordinates } \\
\text { research group(s) related to } \\
\text { PSS theme. }\end{array}$ \\
\hline
\end{tabular}

As it will be presented in the results section, three groups were identified and weightings of $50 \%, 30 \%$ and $20 \%$ were assigned to them. The highest weight was given to the group that, in the view of the authors of this article, have characteristics that enable a better understanding of the theme and consequently those that could provide 
more accurate answers. The definition of groups a priori was necessary in this study for the use of TOPSIS.

TOPSIS was created in 1981 by Ching-Lai Hwang and Kwangsun Yoon (1981) and is being used in several academic studies (Yoon and Kim 2017). This technique stands out for being simple, allowing the comparison of alternatives and considering different criteria according to its importance. In addition, TOPSIS can be used as a tool to substantiate and increase the efficiency of decision making (Lima Junior and Carpinetti 2015). In this study, the "criteria" corresponds to the three groups of respondents and the "alternatives" to the barriers analysed.

The calculations made to ordinate the barriers for PSS operationalization in Brazil via TOPSIS followed the steps proposed by Singh et al. (2016). The first step was characterized by the structuring of a Matrix D, consisting of elements identified as xij, in which (i) represents each alternative - in this research, the barriers - and (j) the analysis criteria - in this research, the averages from the answers of each respondents groups. The mathematical representation of Matrix D is presented by Matrix 1.

$$
D=\left[x_{11} x_{12} \ldots x_{1 n} x_{21} x_{22} \ldots x_{2 n} \ldots \ldots \ldots \ldots x_{m 1} x_{m 2} \ldots x_{m n}\right]
$$

The second step is to normalize Matrix 1 through Equation 1; this gives a new matrix called Matrix R (Matrix 2).

$$
\begin{gathered}
\left.r_{i j}=\frac{x_{i j}}{\sqrt{\sum_{i=1}^{n} x_{i j}^{2}}} \text { (Equation } 1\right) \quad R= \\
{\left[r_{11} r_{12} \ldots r_{1 n} r_{21} r_{22} \ldots r_{2 n} \ldots \ldots \ldots \ldots r_{m 1} r_{m 2} \ldots r_{m n}\right]} \\
\text { The third step carried out was weighting the values of Matrix R }
\end{gathered}
$$
according to the weights assigned to respondents groups, following the guidelines of Singh et al. (2016). For this purpose, Equation 2 and the weights were used, generating Matrix V (Matrix 3). 


$$
\begin{gathered}
v_{i j}=w_{j} * r_{i j} \text { (Equation 2) } \quad V= \\
{\left[v_{11} v_{12} \ldots v_{1 n} v_{21} v_{22} \ldots v_{2 n} \ldots \ldots \ldots \ldots v_{m 1} v_{m 2} \ldots v_{m n}\right] \quad(\text { Matrix 3) }}
\end{gathered}
$$

The fourth step was characterized by the determination of ideal positive $\left(\mathrm{vj}^{+}\right)$ and negative $\left(\mathrm{vj}^{-}\right)$solutions. This step focuses on identifying the maximum and minimum values in Matrix $\mathrm{V}$, for each of the analysis criteria - in this research, for the averages of each group. Once these values were identified, the fifth step was carried out, which corresponded to the calculation of positive $\left(s_{i} *\right)$ and negative $\left(s_{i}{ }^{\prime}\right)$ Euclidean distances for each barrier analysed. Equations 3 and 4 were used for this purpose.

$$
s_{i} *=\sqrt{\Sigma_{j}\left(v_{i j} *-v_{j}^{+}\right)^{2}}(\text { Equation } 3) \quad s_{i}{ }^{\prime}=\sqrt{\sum_{j}\left(v_{i j}{ }^{\prime}-v_{j}^{-}\right)^{2}} \text { (Equation 4) }
$$

After calculating the Euclidean distances, the sixth stage was performed. It was characterized by calculating the $\mathrm{Ci}^{*}$ indicator for each barrier. This indicator can be obtained through Equation 5.

$$
C_{i}^{*}=\frac{s_{i}^{\prime}}{\left(s_{i}^{*}+s_{i}^{\prime}\right)} \quad(\text { Equation 5) }
$$

It is important to note that the value of this indicator varies from 0 to 1 , and it is used for ordering the barriers according to their intensity degree. Once this ordering of the barriers was obtained, the results were discussed in the light of the literature.

\section{Results and discussion}

As mentioned in the previous section, the first analysis corresponded to a Hierarchical

Cluster Analysis in order to identify how respondents are grouped according to their similarities. For this, it was necessary to represent numerically the characteristics of each respondent using the codes presented in Table 2. 
It is important to highlight that for the analysis and formation of the clusters there was no weighting of any of the four coding criteria, that is, experience, greatest academic training completed, research area and participation in a research group associated with PSS had equal weights. Figure 1 shows the result of the Hierarchical Cluster Analysis using the Dendogram.

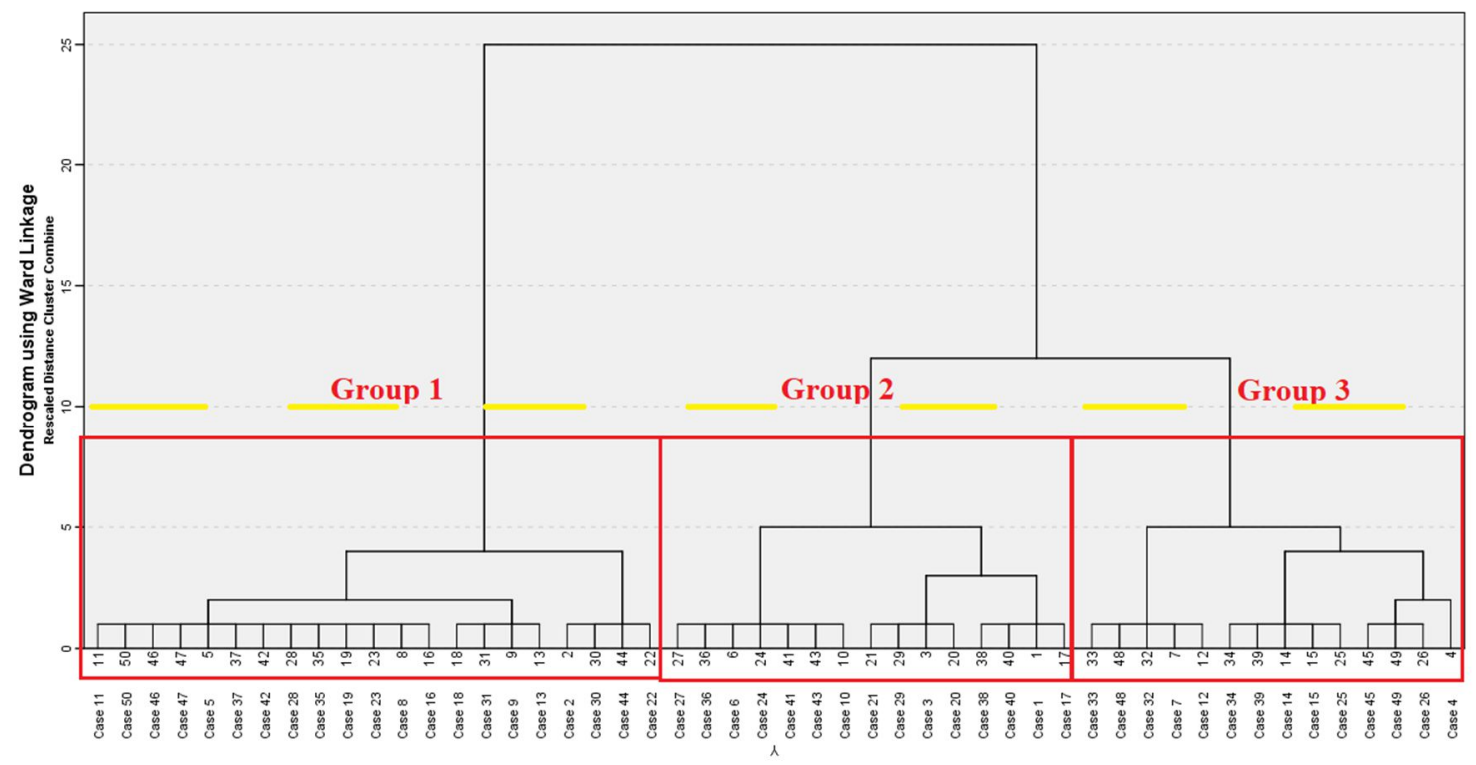

Figure 1. Respondents grouping according to similarity (Source: Authors)

The cut line for defining the groups was established at 10. From the dendogram shown in Figure 2, three groups of respondents were identified. The weights for these were: $20 \%$ for group $1,30 \%$ for group 2 , and $50 \%$ for group 3 . As previously emphasized, the weightings are related to the respondents ability to assess what was asked.

Before the TOPSIS calculus, it is interesting to analyse the averages attributed to each group for studied barriers. Table 3 presents these values. 
Table 3. Averages of scores attributed by respondents, according Hierarquical Cluster grouping. (Source: Authors).

\begin{tabular}{cccccccc}
\hline Barriers & Group & Group & Group & Barriers & Group & Group & Group \\
& $\mathbf{1}$ & $\mathbf{2}$ & $\mathbf{3}$ & & $\mathbf{2}$ & $\mathbf{3}$ \\
\hline B_1 & 7.71 & 6.93 & 7.86 & B_11 & 6.14 & 6.00 & 6.29 \\
B_2 & 7.62 & 6.93 & 6.93 & B_12 & $\mathbf{8 . 5 7}$ & $\mathbf{8 . 3 3}$ & 8.00 \\
B_3 & $\mathbf{5 . 9 5}$ & $\mathbf{5 . 8 7}$ & 6.79 & B_13 & 7.38 & 7.13 & 7.07 \\
B_4 & 7.48 & 7.40 & 7.93 & B_14 & 7.14 & 7.60 & 7.43 \\
B_5 & 7.57 & 7.80 & 7.36 & B_15 & 6.52 & 6.27 & 6.57 \\
B_6 & 7.48 & 8.00 & 7.14 & B_16 & 7.05 & 6.80 & 6.29 \\
B_7 & 7.67 & 7.87 & 7.00 & B_17 & 6.67 & 6.07 & 6.71 \\
B_8 & 8.14 & 8.27 & $\mathbf{8 . 0 7}$ & B_18 & 6.62 & 6.33 & 6.86 \\
B_9 & 7.00 & 6.53 & 6.93 & B_19 & 7.05 & 7.53 & $\mathbf{6 . 1 4}$ \\
B_10 & 7.48 & 6.67 & 7.71 & & & & \\
\hline
\end{tabular}

It is observed that the averages for all groups are above 5.0 - and some exceed 8.0. These values indicate medium or high intensity levels, making it clear that in the Brazilian scenario practically all barriers are evidenced. In a group-by-group analysis, the barrier with the highest average for group 1 is the "Resistance to change for PSS business model", which is also the barrier with the highest average for group 2. For group 3, the barrier with the highest average is "Lack of skills needed for business management". When analysing the barriers with the lowest averages in each group, the following was found: for groups 1 and 2 the barrier "Low performance perspective", and, for group 3, the barrier "Lack of government support for establishing an enabling environment".

In the sequence, TOPSIS was used to obtain the ordering of studied barriers considering groups weighting. From the average scores for each group of respondents, it was possible to structure Matrix D and then standardize it using Equation 1. The matrix obtained is Matrix R. With the weighting of Matrix R, Matrix V was generated. Both matrices are presented in Table 4. 
Table 4. Matrix R with standardized values. (Source: Authors)

\begin{tabular}{ccccccc}
\hline & \multicolumn{3}{c}{ Matrix R } & \multicolumn{3}{c}{ Matrix V } \\
\hline Barriers & $\begin{array}{r}\text { rij } \\
\text { Group 1 }\end{array}$ & $\begin{array}{c}\text { rij } \\
\text { Group 2 }\end{array}$ & $\begin{array}{c}\text { rij } \\
\text { Group 3 }\end{array}$ & $\begin{array}{c}\text { rij } \\
\text { Group 1 } \\
* 0.2\end{array}$ & $\begin{array}{c}\text { rij } \\
\text { Group 2 } \\
* 0.3\end{array}$ & $\begin{array}{c}\text { Group } \\
\text { * } 0.5\end{array}$ \\
\hline B_1 & 0.244 & 0.224 & 0.253 & 0.049 & 0.067 & 0.126 \\
B_2 & 0.241 & 0.224 & 0.223 & 0.048 & 0.067 & 0.111 \\
B_3 & 0.188 & 0.189 & 0.218 & 0.038 & 0.057 & 0.109 \\
B_4 & 0.237 & 0.239 & 0.255 & 0.047 & 0.072 & 0.128 \\
B_5 & 0.240 & 0.252 & 0.237 & 0.048 & 0.075 & 0.118 \\
B_6 & 0.237 & 0.258 & 0.230 & 0.047 & 0.077 & 0.115 \\
B_7 & 0.243 & 0.254 & 0.225 & 0.049 & 0.076 & 0.113 \\
B_8 & 0.258 & 0.267 & 0.260 & 0.052 & 0.080 & 0.130 \\
B_9 & 0.221 & 0.211 & 0.223 & 0.044 & 0.063 & 0.111 \\
B_10 & 0.237 & 0.215 & 0.248 & 0.047 & 0.065 & 0.124 \\
B_11 & 0.194 & 0.194 & 0.202 & 0.039 & 0.058 & 0.101 \\
B_12 & 0.271 & 0.269 & 0.257 & 0.054 & 0.081 & 0.129 \\
B_13 & 0.234 & 0.230 & 0.227 & 0.047 & 0.069 & 0.114 \\
B_14 & 0.226 & 0.245 & 0.239 & 0.045 & 0.074 & 0.119 \\
B_15 & 0.206 & 0.202 & 0.211 & 0.041 & 0.061 & 0.106 \\
B_16 & 0.223 & 0.219 & 0.202 & 0.045 & 0.066 & 0.101 \\
B_17 & 0.211 & 0.196 & 0.216 & 0.042 & 0.059 & 0.108 \\
B_18 & 0.209 & 0.204 & 0.221 & 0.042 & 0.061 & 0.110 \\
B_19 & 0.223 & 0.243 & 0.198 & 0.045 & 0.073 & 0.099 \\
\hline
\end{tabular}

The next step consisted of defining the positive and negative ideal solutions. The Positive Ideal Solutions $\left(\mathrm{vj}^{+}\right)$were $0.054,0.081$, and 0.130 for group 1,2 and 3 , respectively. The Negative Ideal Solutions $\left(\mathrm{vj}^{-}\right)$were $0.038,0.057$, and 0.099 for group 1,2 and 3 , respectively.

The values presented in Tables 4 (Matrix V) and the positive and negative ideal solutions were used to calculate the Euclidean distances for each barrier in relation to the positive and negative ideal solutions; in these calculations, Equations 3 and 4 were used. The values obtained, designated by $\mathrm{Si}^{+}$and $\mathrm{Si}^{-}$, are shown in Table 5. Using these values and Equation 5, it was possible to obtain the $\mathrm{Ci} *$ coefficient also shown in Table 5. 
Table 5. Distances from positive and negative ideal solutions and coefficients $\mathrm{Ci}^{*}$ (Source: Authors)

\begin{tabular}{cccc}
\hline Barriers & $\begin{array}{c}\text { Distance from the Positive } \\
\text { Ideal Solution (Si*) }\end{array}$ & $\begin{array}{c}\text { Distance from the Negative } \\
\text { Ideal Solution (Si') }\end{array}$ & Coefficient (Ci*) \\
\hline B_1 & 0.015 & 0.031 & 0.677 \\
B_2 & 0.024 & 0.019 & 0.451 \\
B_3 & 0.036 & 0.010 & 0.225 \\
B_4 & 0.012 & 0.034 & 0.744 \\
B_5 & 0.014 & 0.029 & 0.672 \\
B_6 & 0.017 & 0.028 & 0.624 \\
B_7 & 0.019 & 0.026 & 0.583 \\
B_8 & 0.003 & 0.041 & 0.937 \\
B_9 & 0.027 & 0.016 & 0.365 \\
B_10 & 0.018 & 0.028 & 0.604 \\
B_11 & 0.040 & 0.003 & 0.068 \\
B_12 & 0.001 & 0.042 & 0.973 \\
B_13 & 0.021 & 0.021 & 0.501 \\
B_14 & 0.015 & 0.028 & 0.642 \\
B_15 & 0.034 & 0.009 & 0.204 \\
B_16 & 0.034 & 0.012 & 0.256 \\
B_17 & 0.033 & 0.010 & 0.239 \\
B_18 & 0.030 & 0.013 & 0.302 \\
B_19 & 0.033 & 0.018 & 0.345 \\
\hline
\end{tabular}

In conclusion, the ordering of barriers for the operationalization of PSS in Brazil was carried out through the values obtained from $\mathrm{Ci}^{*}$. This ordering is shown in Table 6. 
Table 6. Barriers ordering according to coefficients Ci*. (Source: Authors)

\begin{tabular}{ccccc}
\hline Position & Ci* & Code & Barriers \\
\hline $1^{\circ}$ & 0.973 & B_12 & Resistance to change for PSS business model. \\
$2^{\circ}$ & 0.937 & B_8 & Lack of skills needed for business management. \\
$3^{\circ}$ & 0.744 & B_4 & Difficulty in recognizing market demands. \\
$4^{\circ}$ & 0.677 & B_1 & Lack of understanding or misunderstanding of the concept. \\
$5^{\circ}$ & 0.672 & B_5 & Low engagement in innovation activities. \\
$6^{\circ}$ & 0.642 & B_14 & Lack of adequate financial management. \\
$7^{\circ}$ & 0.624 & B_6 & Lack of technological information and knowledge for implementation. \\
$8^{\circ}$ & 0.604 & B_10 & Difficulty in establishing business strategies. \\
$9^{\circ}$ & 0.583 & B_7 & Lack of qualified personnel. \\
$10^{\circ}$ & 0.501 & B_13 & Internal organizational conflicts between sales and service areas. \\
$11^{\circ}$ & 0.451 & B_2 & Lack of financial resources. \\
$12^{\circ}$ & 0.365 & B_9 & Negative prospects due to uncertainties. \\
$13^{\circ}$ & 0.345 & B_19 & Lack of government support for establishing an enabling environment. \\
$14^{\circ}$ & 0.302 & B_18 & Low attractiveness for companies to adopt PSS due to misuse by customers, \\
$15^{\circ}$ & 0.256 & B_16 & compromising financial planning. \\
$16^{\circ}$ & 0.239 & B_17 & Lack of trust and collaboration in the supply chain. \\
$17^{\circ}$ & 0.225 & B_3 & Low management commitment to PSS implementation. \\
$18^{\circ}$ & 0.204 & B_15 & Low performance perspective. \\
$19^{\circ}$ & 0.068 & B_11 & Difficulty in reconciling environmental and social aspects with economic aspects in \\
business.
\end{tabular}

The results obtained through the TOPSIS application clearly highlights two barriers, namely "Resistance to change for PSS business model" and "Lack of skills needed for business management".

Regarding the resistance to change, this result is in line with several studies in the literature and it is mentioned by the both studies which the questionnaire was based on (Annarelli et al. 2016; Jesus Pacheco et al. 2019). It is observed that, as in companies from other parts of the world, many Brazilian companies are unable to leave their comfort zone, even when their traditional business model shows signs of exhaustion. As it is highlighted in Annarelli et al. (2016), PSS operationalization requires changes in 
organizational culture, and in the way companies consider their value. Regarding the "Lack of skills needed for business management", this result also corroborates the literature. In Jesus Pacheco et al. (2019) analysis, the authors emphasize this barrier. According to them, the lack of managerial skills can be associated with lack of planning and difficulty in properly attributing tasks, among other issues. In this sense, it is necessary to address the existing gaps regarding professional training of people able to work in the management of PSS (Annarelli et al. 2016; Jesus Pacheco et al. 2019). As in other parts of the world, it was evidenced that there is a lack of trained professionals in Brazil.

Nevertheless, it is important to highlight that the first two barriers ordered via TOPSIS are related to aspects of "transformation" of both company and professionals, a fact debated in the literature. This is especially true when it is mentioned that business models based on PSS require changes, transformations and innovations in the organization and human capital (Annarelli et al. 2016; Jesus Pacheco et al. 2019).

It is worth highlighting that coping with these barriers will support companies to be better aligned with SDGs 9 and 12 (UN 2019), since PSS are business models that can greatly support companies moving towards more sustainable development (Teles et al. 2018; D’Agostin et al. 2020).

\section{Conclusions}

When analysing the academic literature, there are studies that report barriers regarding the operation of PSS systems. However, these barriers may present different degrees of intensity depending on the country where the business model is implemented. Cultural issues, management typology developed in companies and consumer habits must be considered, and in this sense, specific analysis must be conducted in order to enhance the debates on this topic. The present study aimed to analyse the barriers for 
operationalizing PSS business models in Brazil. The research was based on the opinion of Brazilian academics who have already produced works and studies in the area of PSS and have experience in relation to the theme at different levels. Their opinion received different weights according to their experience level. Based on the results presented, it can be observed that the main objective was achieved.

The main conclusions to be drawn from this study are: 1) in general, even with medium intensity, all the barriers collected in the literature are observed in the Brazilian scenario for PSS operationalization; 2) when a comparison is made among the barriers, those related to resistance to change to the referred business model and the lack of necessary skills to manage them stand out.

In addition to these findings, and considering the literature about the themes, it is possible to observe that the most frequently noted barriers are related to the difficulty presented by companies and professionals to deal with a change in the way their businesses are designed and structured. However, the importance of overcoming these barriers in order to expand and enhance the adoption of PSS business models should be highlighted, especially when considering the relevance that they can have in the search towards sustainable development.

The study had an exploratory character and, as an exploratory study, limitations must be mentioned. The first one related to the barriers analysed; there is a possibility that articles listed in other databases may present additional barriers. However, we highlight that both articles used performed systematic literature reviews and were published in an important database. In addition, the study was based on the opinion of 50 researchers, and a larger sample could provide results with some differences from this one. Nevertheless, the relevance of the information presented here stands to 
enhance debates about PSS in the Brazilian context. Additionally, we emphasize the qualifications of the selected sample.

As a proposal for future work, research in other countries is encouraged and the results obtained to be compared with those presented here. In addition, a roadmap for Brazilian companies to adopt the PSS business model, emphasizing the barriers that, according to the specialists, are more evidenced in the country's reality.

\section{References}

Akbar P, Hoffmann S. 2019. Creating value in product service systems through sharing. J Bus Res.(January):1-11. doi:10.1016/j.jbusres.2019.12.008.

Amiri M, Hashemi-Tabatabaei M, Ghahremanloo M, Keshavarz-Ghorabaee M, Zavadskas EK, Banaitis A. 2020. A new fuzzy BWM approach for evaluating and selecting a sustainable supplier in supply chain management. Int J Sustain Dev World Ecol. 00(00):1-18. doi:10.1080/13504509.2020.1793424. https://doi.org/10.1080/13504509.2020.1793424.

Annarelli A, Battistella C, Nonino F. 2016. Product service system: A conceptual framework from a systematic review. J Clean Prod. 139:1011-1032.

doi:10.1016/j.jclepro.2016.08.061. https://linkinghub.elsevier.com/retrieve/pii/S0959652616312094.

Annarelli A, Battistella C, Nonino F. 2020. Competitive advantage implication of different Product Service System business models: Consequences of 'not-replicable' capabilities. J Clean Prod. 247:119121. doi:10.1016/j.jclepro.2019.119121. https://doi.org/10.1016/j.jclepro.2019.119121.

Ayala NF, Gerstlberger W, Frank AG. 2019. Managing servitization in product companies: the moderating role of service suppliers. Int J Oper Prod Manag. 39(1):43-74. doi:10.1108/IJOPM-08-2017-0484. https://www.emerald.com/insight/content/doi/10.1108/IJOPM-08-2017-0484/full/html.

Baines TS, Lightfoot HW, Evans S, Neely A, Greenough R, Peppard J, Roy R, Shehab E, Braganza A, Tiwari A, et al. 2007. State-of-the-art in product-service systems. Proc Inst Mech Eng Part B J Eng Manuf. 221(10):1543-1552. doi:10.1243/09544054JEM858. 
Bali Swain R, Yang-Wallentin F. 2020. Achieving sustainable development goals: predicaments and strategies. Int J Sustain Dev World Ecol. 27(2):96-106. doi:10.1080/13504509.2019.1692316. https://doi.org/10.1080/13504509.2019.1692316.

Beuren FH, Gomes Ferreira MG, Cauchick Miguel PA. 2013. Product-service systems: a literature review on integrated products and services. J Clean Prod. 47:222-231. doi:10.1016/j.jclepro.2012.12.028. https://linkinghub.elsevier.com/retrieve/pii/S0959652612006841.

Beuren FH, Sousa-Zomer TT, Cauchick-Miguel PA. 2017. Proposal of a framework for product-service systems characterization. Production. 27:1-12. doi:10.1590/01036513.20170052. http://www.scielo.br/scielo.php?script=sci_arttext\&pid=S0103$65132017000100327 \& \operatorname{lng}=\mathrm{en} \& \operatorname{tlng}=\mathrm{en}$.

Boons F, Lüdeke-Freund F. 2013. Business models for sustainable innovation: state-of-the-art and steps towards a research agenda. J Clean Prod. 45:9-19. doi:10.1016/j.jclepro.2012.07.007. https://linkinghub.elsevier.com/retrieve/pii/S0959652612003459.

Boucher X, Brissaud D, Shimomura Y. 2016. Design of sustainable product service systems and their value creation chains. CIRP J Manuf Sci Technol. 15:1-2. doi:10.1016/j.cirpj.2016.09.005. http://dx.doi.org/10.1016/j.cirpj.2016.09.005.

Bradley P, Parry G, O’Regan N. 2020. A framework to explore the functioning and sustainability of business models. Sustain Prod Consum. 21:57-77. doi:10.1016/j.spc.2019.10.007. https://linkinghub.elsevier.com/retrieve/pii/S2352550919302659.

Carvalho JPA de, Ribeiro NP, Franco C da R, Catapan A, Borsato M. 2020. A product-servicesystem proposal for municipalities in developing countries with tight budget to convert the organic waste in energy to eliminate dumps. Waste Manag. 106:99-109. doi:10.1016/j.wasman.2020.03.022. https://doi.org/10.1016/j.wasman.2020.03.022.

Catulli M, Cook M, Potter S. 2017. Consuming use orientated product service systems: A consumer culture theory perspective. J Clean Prod. 141:1186-1193. doi:10.1016/j.jclepro.2016.09.187.

Cegarra-Navarro JG, Papa A, Garcia-Perez A, Fiano F. 2019. An open-minded strategy towards eco-innovation: A key to sustainable growth in a global enterprise. Technol Forecast 
Soc Change. 148(August):119727. doi:10.1016/j.techfore.2019.119727.

Chiu M-C, Tsai C-H. 2020. Design a personalised product service system utilising a multiagent system. Adv Eng Informatics. 43(101):101036. doi:10.1016/j.aei.2020.101036. https://linkinghub.elsevier.com/retrieve/pii/S1474034620300057.

Chofreh AG, Goni FA, Klemeš JJ. 2018. Evaluation of a framework for sustainable Enterprise Resource Planning systems implementation. J Clean Prod. 190:778-786. doi:10.1016/j.jclepro.2018.04.182.

Corrêa HL. 2018. Servitization meets sustainability. :358-364.

Cusumano MA, Kahl SJ, Suarez FF. 2015. Services, industry evolution, and the competitive strategies of product firms. Strateg Manag J. 36(4):559-575. doi:10.1002/smj.2235. http://doi.wiley.com/10.1002/smj.2235.

D’Agostin A, de Medeiros JF, Vidor G, Zulpo M, Moretto CF. 2020. Drivers and barriers for the adoption of use-oriented product-service systems: A study with young consumers in medium and small cities. Sustain Prod Consum. 21:92-103. doi:10.1016/j.spc.2019.11.002. https://linkinghub.elsevier.com/retrieve/pii/S2352550919301381.

Franciosi C, Voisin A, Miranda S, Riemma S, Iung B. 2020. Measuring maintenance impacts on sustainability of manufacturing industries: from a systematic literature review to a framework proposal. J Clean Prod. 260:121065. doi:10.1016/j.jclepro.2020.121065. https://linkinghub.elsevier.com/retrieve/pii/S0959652620311124.

Homrich AS, Theodoro DS, Carvalho MM de. 2017. PSS Creating Business for Sustainability: The Brazilian Olive Oil Case in Mantiqueira Community. Procedia CIRP. 64:405-410. doi:10.1016/j.procir.2017.03.110. http://dx.doi.org/10.1016/j.procir.2017.03.110.

Hwang C-L, Yoon K. 1981. Multiple Attribute Decision Making. Berlin, Heidelberg: Springer Berlin Heidelberg (Lecture Notes in Economics and Mathematical Systems). http://link.springer.com/10.1007/978-3-642-48318-9.

Jesus Pacheco DA, ten Caten CS, Jung CF, Sassanelli C, Terzi S. 2019. Overcoming barriers towards Sustainable Product-Service Systems in Small and Medium-sized enterprises: State of the art and a novel Decision Matrix. J Clean Prod. 222:903-921. doi:10.1016/j.jclepro.2019.01.152. https://doi.org/10.1016/j.jclepro.2019.01.152.

Lermen FH, Ribeiro JLD, Echeveste ME, Milani Martins VL, Tinoco MAC. 2020. Sustainable 
offers for drying and storage of grains: Identifying perceived value for Brazilian farmers. J Stored Prod Res. 87. doi:10.1016/j.jspr.2020.101579.

Lima Junior FR, Carpinetti LCR. 2015. Uma comparação entre os métodos TOPSIS e FuzzyTOPSIS no apoio à tomada de decisão multicritério para seleção de fornecedores. Gestão \& Produção. 22(1):17-34. doi:10.1590/0104-530X1190. http://www.scielo.br/scielo.php?script=sci_arttext\&pid=S0104$530 X 2015000100017 \& \operatorname{lng}=$ pt\&tlng $=$ pt.

Malhotra NK. 2012. Pesquisa de Marketing. Uma orientação aplicada. 6th ed. Porto Alegre: Bookman.

Martins VWB, Rampasso IS, Siltori PFS, Cazeri GT, Quelhas OLG. 2020. Contributions from the Brazilian industrial sector to Sustainable Development. J Clean Prod. 272:122762. doi:10.1016/j.jclepro.2020.122762. https://doi.org/10.1016/j.jclepro.2020.122762.

Mont O, Dalhammar C, Jacobsson N. 2006. A new business model for baby prams based on leasing and product remanufacturing. J Clean Prod. 14(17):1509-1518. doi:10.1016/j.jclepro.2006.01.024.

Mont OK. 2019. Clarifying the Concept of Smart Service System. 10:349-376. doi:10.1007/978-3-319-98512-1_16.

Oliveira MG de, Mendes GH de S, Albuquerque AA de, Rozenfeld H. 2018. Lessons learned from a successful industrial product service system business model: emphasis on financial aspects. J Bus Ind Mark. 33(3):365-376. doi:10.1108/JBIM-07-2016-0147.

Omer A, Elagib NA, Zhuguo M, Saleem F, Mohammed A. 2020. Water scarcity in the Yellow River Basin under future climate change and human activities. Sci Total Environ.:141446. doi:10.1016/j.scitotenv.2020.141446. https://doi.org/10.1016/j.scitotenv.2020.141446.

Ordonez-Ponce E, Khare A. 2020. GRI 300 as a measurement tool for the United Nations sustainable development goals: assessing the impact of car makers on sustainability. $\mathrm{J}$ Environ Plan Manag. 0(0):1-29. doi:10.1080/09640568.2020.1746906. https://doi.org/10.1080/09640568.2020.1746906.

Park H, Yoon J. 2015. A chance discovery-based approach for new product-service system (PSS) concepts. Serv Bus 9.:115e135.

Pereira VR, Kreye ME, Carvalho MM de. 2019. Customer-pulled and provider-pushed 
pathways for product-service system. J Manuf Technol Manag. 30(4):729-747.

doi:10.1108/JMTM-07-2018-0209.

https://www.emerald.com/insight/content/doi/10.1108/JMTM-07-2018-0209/full/html.

Pezzotta G, Sala R, Pirola F, Campos AR, Margarito A, Correia AT, Fotia S, Mourtzis D. 2016.

Definition of a PSS engineering environment: From the theoretical methodology to the platform implementation. Proc Summer Sch Fr Turco. 13-15-Sept:97-101.

Reigado CR, Fernandes SDC, Saavedra YMB, Ometto AR, Costa JMH da. 2017. A Circular

Economy Toolkit as an Alternative to Improve the Application of PSS Methodologies.

Procedia CIRP. 64:37-42. doi:10.1016/j.procir.2017.03.034.

https://linkinghub.elsevier.com/retrieve/pii/S2212827117301786.

Shete PC, Ansari ZN, Kant R. 2020. A Pythagorean fuzzy AHP approach and its application to evaluate the enablers of sustainable supply chain innovation. Sustain Prod Consum. 23:77-93. doi:10.1016/j.spc.2020.05.001. https://doi.org/10.1016/j.spc.2020.05.001.

Singh RK, Gupta A, Kumar A, Khan TA. 2016. Ranking of barriers for effective maintenance by using TOPSIS approach. J Qual Maint Eng. 22(1):18-34. doi:10.1108/JQME-022015-0009. http://www.emeraldinsight.com/doi/10.1108/JQME-02-2015-0009.

Sousa-Zomer TT, Miguel PAC. 2016. Exploring the Critical Factors for Sustainable Productservice Systems Implementation and Diffusion in Developing Countries: An Analysis of two PSS Cases in Brazil. Procedia CIRP. 47:454-459. doi:10.1016/j.procir.2016.03.061. http://dx.doi.org/10.1016/j.procir.2016.03.061.

Sousa TT, Miguel PAC. 2015. Product-service Systems as a Promising Approach to Sustainability: Exploring the Sustainable Aspects of a PSS in Brazil. Procedia CIRP. 30:138-143. doi:10.1016/j.procir.2015.02.025. https://linkinghub.elsevier.com/retrieve/pii/S2212827115000645.

Teles F, Gomes Magri RT, Cooper Ordoñez RE, Anholon R, Lacerda Costa S, Santa-Eulalia LA. 2018. Sustainability measurement of product-service systems: Brazilian case studies about electric car-sharing. Int J Sustain Dev World Ecol. 25(8):721-728. doi:10.1080/13504509.2018.1488771. https://doi.org/10.1080/13504509.2018.1488771.

Tukker A. 2015. Product services for a resource-efficient and circular economy - a review. J Clean Prod. 97:76-91.

UN. 2015. Sustainable Development Goals (SDGs). [accessed 2019 May 1]. 
https://www.un.org/sustainabledevelopment/sustainable-development-goals/.

UN. 2019. Global indicator framework for the Sustainable Development Goals and targets of the 2030 Agenda for Sustainable Development. :21. [accessed 2019 Jun 4]. https://unstats.un.org/sdgs/indicators/Global Indicator Framework after 2019 refinement_Eng.pdf.

Vezzoli C, Ceschin F, Diehl JC, Kohtala C. 2015. New design challenges to widely implement “Sustainable Product-Service Systems.” J Clean Prod. 97:1-12. doi:10.1016/j.jclepro.2015.02.061. http://dx.doi.org/10.1016/j.jclepro.2015.02.061.

Weking J, Brosig C, Böhm M, Hein A, Kremar H. 2018. Business Model Innovation Strategies for Product Service Systems - an Explorative Study. In: EUROPEAN CONFERENCE ON INFORMATION SYSTEMS (ECIS). Twenty-Sixth European Conference on Information Systems (ECIS2018), Portsmouth,UK, 2018.

Yang M, Evans S. 2019. Product-service system business model archetypes and sustainability. J Clean Prod. 220:1156-1166. doi:10.1016/j.jclepro.2019.02.067. https://linkinghub.elsevier.com/retrieve/pii/S0959652619304524.

Yoon KP, Kim WK. 2017. The behavioral TOPSIS. Expert Syst Appl. 89:266-272. doi:10.1016/j.eswa.2017.07.045. http://dx.doi.org/10.1016/j.eswa.2017.07.045.

Zeeuw van der Laan A, Aurisicchio M. 2020. A framework to use product-service systems as plans to produce closed-loop resource flows. J Clean Prod. 252:119733. doi:10.1016/j.jclepro.2019.119733. https://linkinghub.elsevier.com/retrieve/pii/S0959652619346037.

Zhang Y, Sun J, Yang Z, Wang Y. 2020. Critical success factors of green innovation: Technology, organization and environment readiness. J Clean Prod. 264:121701. doi:10.1016/j.jclepro.2020.121701. 